Bangladesh J. Bot. 50(3): 933-938, 2021 (September) SpecialＤOI: https://doi.org/10.3329/bjb.v50i5.56447

\title{
GROWTH RESPONSES OF SORGHUM BICOLOR (L.) MOENCH TO ARBUSCULAR MYCORRHIZAL FUNGI UNDER SIMULATED NITROGEN DEPOSITION
}

\author{
JiAN WANG ${ }^{1,2,3,4}$, ChenXI YANG ${ }^{1,2,3,4}$, XIAOMEI SuN $^{1,2,3,4}$, HAIOU ZHANG $^{1,2,3,4}$, \\ Zhen Guo ${ }^{1,2,3,4}$, Tingting CaO ${ }^{1,2,3,4}$ and Juan Li ${ }^{1,2,3,4^{*}}$ \\ Institute of Land Engineering and Technology, Shaanxi Provincial Land Engineering \\ Construction Group Co., Ltd., Xi'an, Shaanxi 710075, China
}

Keywords: Nitrogen deposition, AMF, Sorghum bicolor (L.) Moench, Growth performance

\begin{abstract}
Anthropogenic nitrogen $(\mathrm{N})$ deposition leads to a dramatically increase in biologically available $\mathrm{N}$ in many ecosystems, which can change the symbiotic relationship between AMF and host plants. However, how and to what extent exogenous N-induced AMF could affect plants remains poorly understood. In this work, mycorrhizal growth responses of Sorghum bicolor to AMF under simulated N deposition were conducted in a glasshouse experiment. Results demonstrated that AMF elevated the growth performance and nutrient uptake $(\mathrm{N}, \mathrm{P})$ of S. bicolor at almost all treatments, although mycorrhizal colonization decreased with $\mathrm{N}$ addition. In addition, mycorrhizal response (MR) showed identical trend of first fall and then increase, and the lowest value was at the N1 treatment. The present study provided the first pot-based evidence that AMF can alleviate the mischief induced by high $\mathrm{N}$ addition, implying that AMF has a considerable significance in the farmland ecosystem under anthropogenic $\mathrm{N}$ deposition.
\end{abstract}

\section{Introduction}

With the massive burning of fossil fuels and excessive use of nitrogen $(\mathrm{N})$ fertilizers, the $\mathrm{N}$ content at the atmosphere has been increased sharply since the middle of the 20th century (Kontunen-Soppela et al. 2000). Relevant studies have shown that the $\mathrm{N}$ deposition has reached more than $30 \mathrm{~kg} \mathrm{~N} \mathrm{hm}^{-1} \mathrm{a}^{-1}$ in the North China Plain in 2010 (Zheng et al. 2014). The increase in soil $\mathrm{N}$ content caused by $\mathrm{N}$ deposition has also brought a series of severe ecological and environmental problems. The impact of $\mathrm{N}$ on land plants has also attracted more attention to the scientists (Sun et al. 2015, Yi et al. 2016).

$\mathrm{N}$ is an essential element for plant growth and participates in important physiological and biochemical reactions in the entire life of plants. Hao et al. (2014) reported that the introduction of external $\mathrm{N}$ can promote plant growth in $\mathrm{N}$-deficient areas, but inhibit plant growth in N-rich areas, and directly affect the diversity of ecosystems to a certain degree.

Arbuscular mycorrhizal fungi (AMF) are widely distributed in nature and can form symbiotic mycorrhizas with more than $80 \%$ of terrestrial vascular plants (Smith and Read 2008). AMF can transfer the absorbed water and mineral nutrients to the host plant, and plants conversely transport carbohydrates synthesized by photosynthesis to AMF as carbon sources. This symbiotic relationship not only enhances the absorption of nutrients by plants but also improves their ability

\footnotetext{
*Author for correspondence: <jianwang2015@1zu.edu.cn>. 1Shaanxi Provincial Land Engineering Construction Group Co., Ltd., Xi'an 710075, China. 2Key Laboratory of Degraded and Unused Land Consolidation Engineering, the Ministry of Natural and Resources of China, Shaanxi, Xi' an 710075, China. 3Shaanxi Provincial Land Consolidation Engineering Technology Research Center, Shaanxi, Xi' an 710075, China. 4Shaanxi Key Laboratory of Land Consolidation, Xi' an 710064, China.
} 
to resist adversity to a certain extent (van der Heijden et al. 2015). Compared with the $\mathrm{N}$ absorption by plant roots, the mycorrhiza formed by AMF reshape the structure of the root system and expand the absorption range of roots, which increase the absorption capacity of host plant roots for nutrients such as N and phosphorus (P) (Hodge and Fitter. 2010). Simultaneously, Xue et al. (2004) found that soil $\mathrm{N}$ content can significantly affect the ability of AMF to infect plant roots. The increase of soil $\mathrm{N}$ content can increase the mycorrhizal infection rate in $\mathrm{N}$-deficient areas and reduce the mycorrhizal infection rate in N-rich areas.

S. bicolor is a common coarse grain crop in northern China. Considering its close symbiosis relationship with AM fungi, it is often used as research material for AM fungi expansion and inoculation experiments (Yamato et al. 2008). Hence, the present study was conducted to evaluate the effect of AMF under simulated $\mathrm{N}$ deposition to the growth responses of $S$. bicolor in greenhouse conditions.

\section{Materials and Methods}

The AMF (Funneliformis coronaturm) (Schüßler and Walker 2010) inoculum in the form of spores and infected roots of Sorghum (approximately 150 spores per gram inoculum) were obtained from the department of school of life science, Lanzhou University, Lanzhou, Gansu, China. Seeds of S. bicolor collected from the Shaanxi Prefecture Institute of Agronomy, was disinfected with $0.5 \% \mathrm{NaClO}$ solution for $100 \mathrm{~s}$, rinsed with running water, and soaked in distilled water for $10 \mathrm{~min}$, after that the germination in a $25^{\circ} \mathrm{C}$ constant temperature light incubator was accelerated (Bahadur et al. 2019). Germinative seeds were sown in a seedling pot $(16 \times 14 \mathrm{~cm})$.

Soil collected from an arid agriculture demonstration area with an $\mathrm{N}$ deposition background value of $27.6 \mathrm{~kg} \mathrm{~N} / \mathrm{hm} / \mathrm{a}$, was sieved through a $2 \mathrm{~mm}$ mesh as a pot substrate. Each inoculated pot $(+\mathrm{AMF})$ received $10 \mathrm{~g}$ of inoculum, and non-inoculated pot (-AMF) were applied with an equal amount of sterilized inoculum. To minimize differences in microbial communities and nutrient between + AMF and -AMF treatments, $10 \mathrm{ml}$ of AMF -free soil filtrate was added to each noninoculated pot.

The plant seeding was thinned to five plants per pot. Three levels of $\mathrm{N}$ fertilization $(0,30$ and $60 \mathrm{~g} \mathrm{~kg} \mathrm{~N} \mathrm{hm}^{-1} \mathrm{a}^{-1}$; hereafter referred to as N0, N1 and N2, respectively) were selected for this experiment. The $\mathrm{N}$ addition gradient was generated with different amounts of $\mathrm{NH}_{4} \mathrm{NO}_{3}$ fertilizer. The $150 \mathrm{ml}$ of quantitative $\mathrm{N}$ addition solution was poured once every 15 days per pot, and $\mathrm{N}$ addition was applied 10 times in total. The pots were watered every 3 days with $100 \mathrm{ml}$ water each time throughout the experimental period. Hoagland solution was applied per pot to fulfill the increasing nutrient demand of the plants once a week.

The experiment was arranged in a factorial randomized complete design with two factors. The first factor was AMF inoculation treatment (-AMF and $+\mathrm{AMF}$ ), and the second factor was $\mathrm{N}$ fertilization treatment $(\mathrm{N} 0, \mathrm{~N} 1, \mathrm{~N} 2)$. Thence, 6 treatments and 5 replicates of each treatment, were generated yielding a total of 30 pots. The experiment was carried out in the greenhouse of Institute of Land Engineering and Technology, Shaanxi Srovincial Land Engineering Construction Group Co., Ltd., Shaanxi P.R., China from May 15, 2020 to July 30, 2020. The temperature was maintained between 18 and $25^{\circ} \mathrm{C}$ and photoperiod hrs $14 / 10$ (day/night) with $25 \%$ relative humidity and the average of $120 \mu \mathrm{mol} / \mathrm{m}^{2} / \mathrm{s}$ photosynthetic photon flux (PPF).

At the end of the experiment, plant shoots and roots were carefully separated. The fresh roots were cut into $1 \mathrm{~cm}$ segments in length and stained and mycorrhizal colonization was determined by examining root segments under the microscope (200x) (Bahadur et al. 2019). Subsequently, the shoots and remaining roots were kept in the oven for $48 \mathrm{hrs}$ at $80^{\circ} \mathrm{C}$ (Fariduddin et al. 2014), and then used for the determination of dry weight and shoot $\mathrm{N}$ and $\mathrm{P}$ content. 
The mycorrhizal growth response (MGR), mycorrhizal N-uptake response (MNR) and Puptake response (MPR) of plants were used to evaluate the effect of AMF to plant biomass and tissue contents of $\mathrm{N}$ or $\mathrm{P}$ under different $\mathrm{N}$ treatments, and they were calculated according to the formulas of Veiga et al. (2011) and Jiang et al. (2018).

Statistical analyses were carried out using IBM SPSS Statistics 19.0 (StatSoft Inc., Tulsa, USA). All measured data were tested for normality before data analysis. The effects of $\mathrm{N}$ and AMF treatments on root length colonization, plant biomass and N/P content were analyzed using linear mixed-effects models. " $\mathrm{t}$-test" was used to analysis significant differences in biomass, $\mathrm{N}$ and P content, MGR, MPR and MNP of S. bicolor between +AMF and -AMF treatments.

\section{Results and Discussion}

Mycorrhizal colonization of -AMF treatments was zero in all cases, but all +AMF pots showed high levels of colonization (Fig.1). $\mathrm{N}$ addition significantly affect the root length colonization (RLC) (Fig.1a; $F=4.2, P=0.023$ ) and vesicles colonization (VC) (Fig.1c; $F=6.4, P$ $=0.004$ ) except for arbuscular colonization (AC) (Fig.1b; $F=2.4, P=0.102$ ). The RLC has a downward trend with the $\mathrm{N}$ application; the highest RLC at N0 (66.78\%), and the lowest at N1 (47.56\%). Similarly, the highest VC was discovered at N0 (38.05\%), and observed lowest at N1 (22.81\%). The decrease of mycorrhizal colonization with $\mathrm{N}$ addition due to $\mathrm{N}$ enrichment of systems reduces host plant carbon allocation to AMF (Johnson 2010).

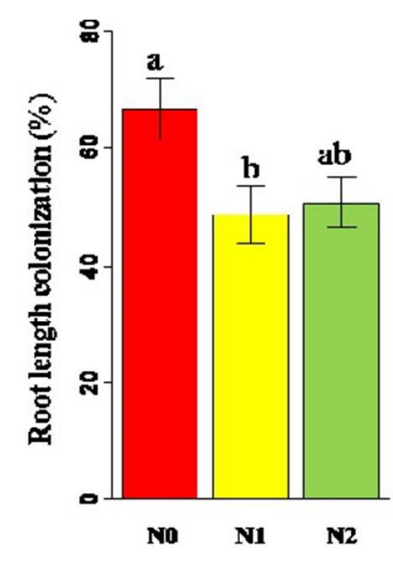

(a)

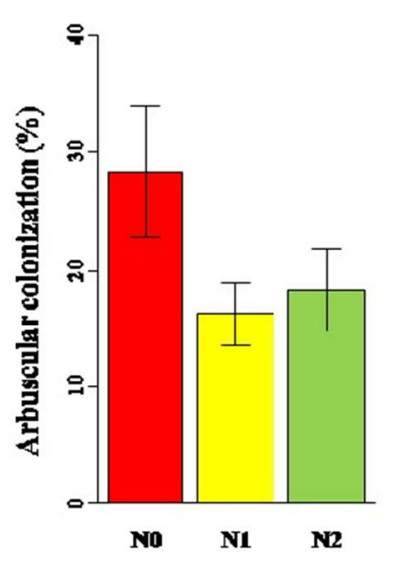

(b) $\mathbf{N}$ fertilization

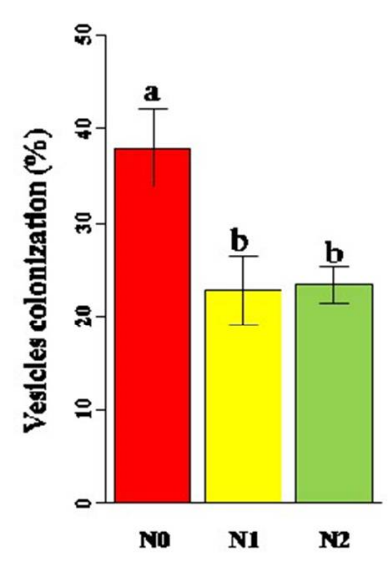

(c) $\quad \mathrm{N}$ fertilization

Fig.1. Effects of nitrogen (N) addition and AMF inoculation on mycorrhizal root colonization. (a). Root length colonization (RLC), (b). Arbuscular colonization (AC) and (c). Veslcles colonization (VC). Bars represent means \pm se $(\mathrm{n}=5)$. Different letters represent significant difference $(P<0.05)$ between bars.

Both AMF inoculum and $\mathrm{N}$ addition had a significant effect on plant total biomass, shoot and root biomass (all $P<0.05$ ). Inoculation with AMF significantly increased $S$. bicolor total biomass, shoot and root biomass at a same $\mathrm{N}$ addition level except for root biomass at $\mathrm{N} 1$ treatment. Interestingly, shoot, root and total biomass of S. bicolor increased by about 3 times at the $\mathrm{N} 0$ and $\mathrm{N} 2$ treatment after inoculating AMF, while they increased by less than double at the NI treatment (Fig. 2). It is understood that $\mathrm{N}$ and $\mathrm{P}$ are important elements to participate metabolism and synthesis of tissues of organs. Increased biologically available N, P uptake through AMF extra- 
mycelium might have contributed to increase synthesis of prerequisite of chlorophyll and enhanced photosynthesis, and eventually lead to an increase in biomass (Begum et al. 2019).

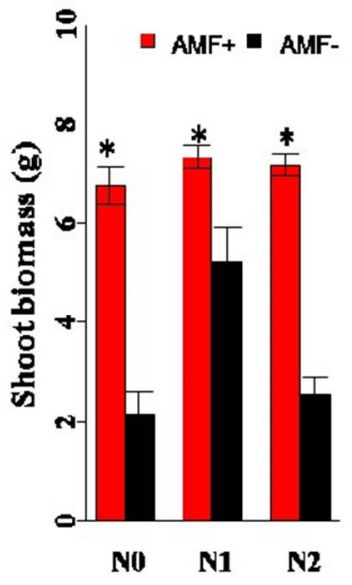

(a) $\mathrm{N}$ fertilization

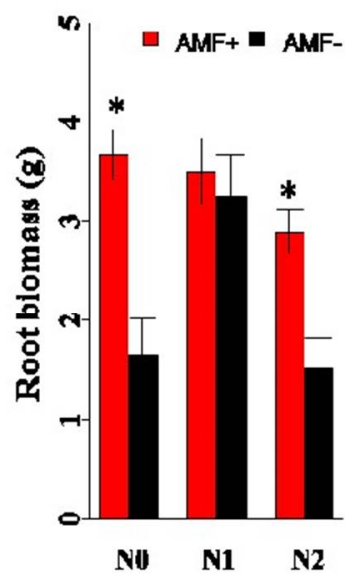

(b) $\mathrm{N}$ fertilization

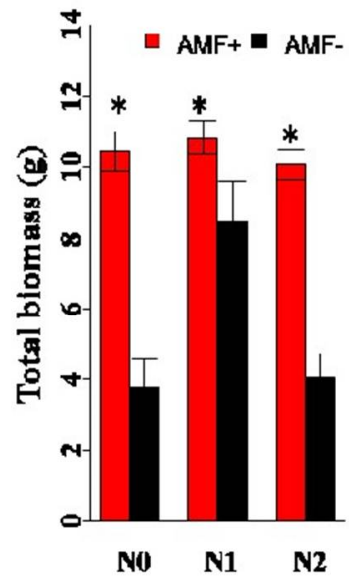

(c) $\mathbf{N}$ fertilization

Fig. 2. Effects of nitrogen (N) addition and AMF inoculation on biomass of S. bicolor. (a). Shoot biomass,

(b). Root biomass and (c). total biomass. Bars represent means \pm se $(n=5)$. $*$ indicate significant difference between + AMF and $-\mathrm{AMF}$ treatment $(P<0.05)$.

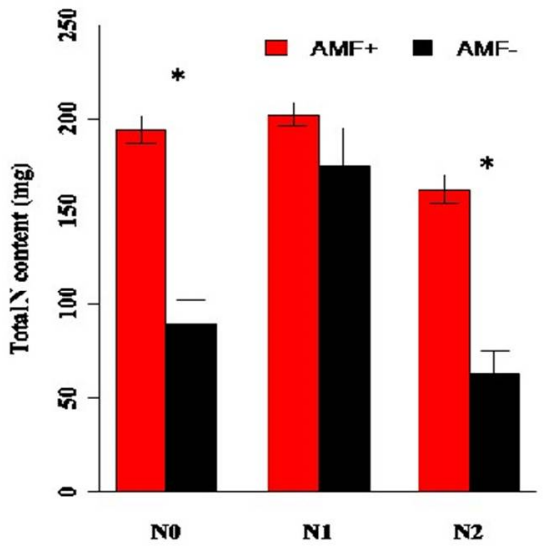

(a)

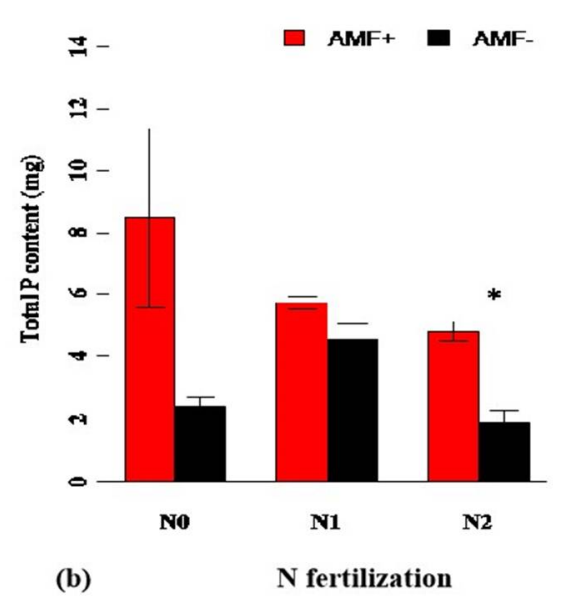

Fig. 3. Effects of nitrogen $(\mathrm{N})$ addition and AMF inoculation on total $\mathrm{N}$ and $\mathrm{P}$ content of S. bicolor. (a) total nitrogen $(\mathrm{N})$ content and (b) total phosphorus $(\mathrm{P})$ content. Bars represent means $\pm \mathrm{se}(\mathrm{n}=5)$. * indicate significant difference between $+\mathrm{AMF}$ and $-\mathrm{AMF}$ treatment $(P<0.05)$.

Inoculation with AMF lead to a significant total $\mathrm{N}$ content increase in all cases except $\mathrm{N} 1$ treatment. Under N0 treatment, inoculating AMF increased the total N content more than twice, rise from 86.77 to $191.65 \mathrm{mg}$ per pot, and the total $\mathrm{N}$ content more than doubled (Fig.3a). Analogously, total $\mathrm{N}$ content were significantly lower on -AMF than on +AMF treatment under $\mathrm{N} 2$ treatment (Fig.3a). According to the results of linear mixed-effects models, inoculating AMF significantly affect issue total $\mathrm{P}$ content (Fig.3b), while $\mathrm{N}$ addition showed no statistically significance (Fig.3b). Compared to N0 and N1 treatment, significant difference was discovered 
according to the t-test (Fig.3b). Inoculation with AMF help to establish a mutually beneficial symbiotic relationship between AMF and host plant, by which AMF provide inorganic nutrients to host plant (van der Heijden et al. 1998). This is why total N and P content of S. bicolor in +AMF treatment was significantly higher than -AMF treatment.

Figure 4 showed that AMF have a positive effect on MGR, MNR and MPR of S. bicolor and MR except MNR at N1 treatment. MR all showed a trend of first decreasing and then increasing, and the lowest value was at N1 treatment. Jiang et al. (2018) showed that MR declined with N addition. However, in the present study MR strangely increased instead of continuing to decline with the $\mathrm{N}$ gradient continued to increase. There are two possible reasons for the analysis: on one hand, AMF need numerous $\mathrm{N}$ for their survival, presumably by which alleviates the stress of high soil $\mathrm{N}$ levels on the host plant (Castellanos-Morales et al. 2010). On the other hand, AMF can improve the absorption of $\mathrm{P}$ to better maintain the $\mathrm{N}$ to phosphorus ratio of the plant, thereby helping the host plant to resist the stress of high $\mathrm{N}$.

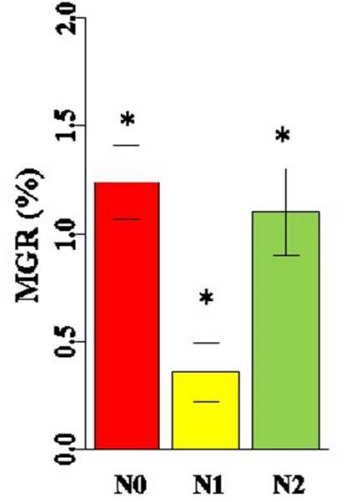

(a) $\mathbf{N}$ fertilization

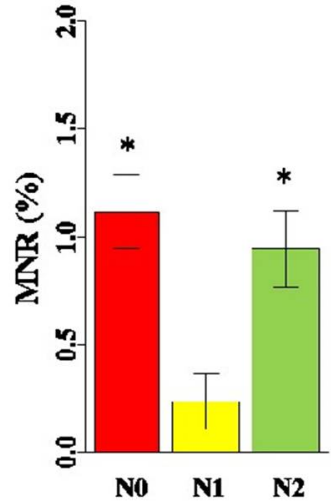

(b) $\quad \mathrm{N}$ fertilization

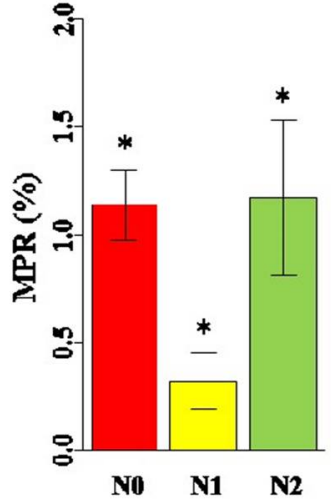

(c) $\quad \mathrm{N}$ fertilization

Fig.4. Mycorrhizal growth response (MGR, a), mycorrhizal N uptake response (MNR, b) and mycorrhizal P uptake response (MPR, c) of $S$. bicolor in glasshouse. * indicates a significant difference between the mycorrhizal response and zero according to $t$-test $(P<0.05)$.

It may be interred that AMF improved the growth performance and nutrient uptake $(\mathrm{N}, \mathrm{P})$ of $S$. bicolor at almost all treatment. Furthermore, it also demonstrated that $\mathrm{N}$ addition induced a great shift on MGR, MNR and MPR, which unanimously reduced first and escalated later. In addition, the present study also provided the first pot-based evidence that AMF can alleviate the mischief induced by high $\mathrm{N}$ addition, implying that AMF has an considerable significance in the farmland ecosystem under gradually increased anthropogenic $\mathrm{N}$ deposition. Considering the ecological significance of AM symbiosis in nature, future studies are needed to address how and to what extent $\mathrm{N}$-induced AMF could affect crop growth in the field test.

\section{Acknowledgements}

The work was supported by the Shaanxi Province Innovative Talent Promotion Plan-Science and Technology Rising Star Project (2021KJXX-88), Shaanxi science and technology association enterprise innovation and youth talent promotion project (2021-1-2), Scientific Research Item of Shaanxi Provincial Land Engineering Construction Group Co., Ltd. (DJNY2020-13). 


\section{References}

Bahadur A, Jin ZC, Long XL, Jiang SJ, Zhang Q, Pan JB and Feng HY 2019. Arbuscular mycorrhizal fungi alter plant interspecific interaction under nitrogen fertilization. Europ. J. of Soil Biology. 93: 103094.

Begum N, Ahanger M, Su Y, Lei YA. Mustafa N, Ahmad P and Zhang L 2019. Improved Drought Tolerance by AMF Inoculation in Maize (Zea mays) Involves Physiological and Biochemical Implications. Plants 8: 579.

Castellanos-Morales V, Villegas J, Wendelin S, Vierheilig H, Eder R and Cárdenas-Navarro R 2010. Root colonisation by the arbuscular mycorrhizal fungus glomus intraradices alters the quality of strawberry fruits (fragaria $\times$ ananassa duch.) at different nitrogen levels. J. Sci. Food Agricul. 90(11): 1765-1958.

Fariduddin Q, Mir BA, Yusuf M and Ahmad A 2014. 24- epibrassinolide and or putrescine trigger physiological and biochemical responses for the salt stress mitigation in Cucumis sativus L. Photosynthetica 52(3): 464-474.

Hao L, Wang Q, Liu T and Xu L 2014. Effect of exponential fertilization on biomass allocation, photosynthesis and root morphology of padus maackii seedlings. Scientia Silvae Sinicae 50(11): 175181.

Hodge A and Fitter AH 2010. Substantial nitrogen acquisition by arbuscular mycorrhizal fungi from organic material has implications for N cycling. Proc. Natl. Acad. Sci. USA. 107: 13754-13759.

Jiang SJ, Liu YJ, Luo JJ, Qin MS, Johnson, NC and ÖPik M, Vasar M, Chai YX, Zhou XL, Mao L, Du GZ, An LZ, Feng HY 2018. Dynamics of arbuscular mycorrhizal fungal community structure and functioning along a nitrogen enrichment gradient in an alpine meadow ecosystem. New Phytologist 220(4): 1222-1235.

Johnson NC 2010. Resource stoichiometry elucidates the structure and function of arbuscular mycorrhizas across scales. New Phytologist 185: 631-647.

Kontunen-Soppela S, Taulavuori K, Taulavuori E, Lhdesmki P and Laine K 2000. Soluble proteins and dehydrins in nitrogen-fertilized scots pine seedlings during deacclimation and the onset of growth. Physiologia Plantarum 109(4): 404-409.

Schüßler A and Walker C 2010. The Glomeromycota - a species list. Gloucester, England. pp.57.

Smith SE and Read DJ 2008. Mycorrhizal Symbiosis, third ed. Academic Press, London. pp.13.

Sun T, Dong L and Mao Z 2015. Simulated atmospheric nitrogen deposition alters decomposition of ephemeral roots. Ecosystems 18(7): 1240-1252.

van der Heijden MG, Martin FM, Selosse MA and Sanders IR 2015. Mycorrhizal ecology and evolution: the past, the present, and the future. New Phytologist 205: 1406-1423.

van der Heijden MGA, Boller T, Wiemken A and Sanders IR 1998. Different arbuscular mycorrhizal fungal species are potential determinants of plant community structure. Ecol. 79: 2082-2091.

Veiga RSL Jansa, J, Frossard E, van der Heijden MGA 2011. Can arbuscular mycorrhizal fungi reduce the growth of agricultural weeds? PLoS ONE 6, e27825.

Xue JH, Mo JM, Li J, Fang YT and Li DJ 2004. Effects of nitrogen deposition on ectomycorrhizal fungi. Acta Ecologica Sinica 24(8):1785-1792.

Yamato M, Ikeda S and Iwase K 2008. Community of arbuscular mycorrhizal fungi in a coastal vegetation on Okinawa Island and effect of the isolated fungi on growth of sorghum under salt-treated conditions. Mycorrhiza 18(5): 241-249.

Yi L, Schichtel BA, Walker JT, Schwede DB and Collett JL 2016. Increasing importance of deposition of reduced nitrogen in the United States. Natl. Acad. Sci. USA. 113(21): 5874-5879.

Zheng DN, Wang XS, Xie SD, Duan L and Chen DS 2014. Simulation of atmospheric nitrogen deposition in China in 2010. China Environmental Science 34(5): 1089-1097. 